\title{
The Maze-Making and Solving Technique for Coil Embolization of Large and Giant Aneurysms
}

\author{
T. Ohta, I. Nakahara, R. Ishibashi, S. Matsumoto, M. Gomi, H. Miyata, H. Nishi, S. Watanabe, and I. Nagata
}

\begin{abstract}
BACKGROUND AND PURPOSE: Despite major progress in treating aneurysms by coil embolization, the complete occlusion of aneurysms of $>10 \mathrm{~mm}$ in diameter (large/giant aneurysms) remains challenging. We present a novel endovascular treatment method for large and giant cerebral aneurysms called the "maze-making and solving" technique and compare the short-term follow-up results of this technique with those of conventional coil embolization.
\end{abstract}

MATERIALS AND METHODS: Eight patients (65 \pm 11.5 years of age, 7 women) with large/giant unruptured nonthrombosed cerebral aneurysm (mean largest aneurysm dimension, $19 \pm 4.4 \mathrm{~mm}$ ) were treated by the maze-making and solving technique, a combination of the double-catheter technique and various assisted techniques. The coil-packing attenuation, postoperative courses, and recurrence rate of this maze group were compared with 30 previous cases (conventional group, $65.4 \pm 13.0$ years of age; 22 women; mean largest aneurysm dimension, $13.4 \pm 3.8 \mathrm{~mm}$ ).

RESULTS: Four maze group cases were Raymond class 1; and 4 were class 2 as indicated by immediate postsurgical angiography. No perioperative deaths or major strokes occurred. Mean packing attenuation of the maze group was significantly higher than that of the conventional group $(37.4 \pm 5.9 \%$ versus $26.2 \pm 5.6 \%$ ). Follow-up angiography performed at $11.3 \pm 5.4$ months revealed no recurrence in the maze group compared with $39.2 \%$ in the conventional group.

CONCLUSIONS: The maze-making and solving technique achieves high coil-packing attenuation for efficient embolization of large and giant cerebral aneurysms with a low risk of recurrence.

S ubstantial progress in the endovascular treatment of cerebral aneurysms, such as balloon- and stent-assisted coil embolization, has resulted in the widespread use of these techniques with relatively high efficacy and safety. However, large and giant aneurysms remain difficult to treat by using assist techniques and bioactive coils, ${ }^{1,2}$ possibly because the requisite coil-packing attenuation is often not achieved. We recently developed a "maze-making and solving" technique to occlude these large/giant aneurysms by achieving high packing attenuation. Here, we present the technical details of this procedure and compare the clinical outcomes and recurrence rates between large/giant aneurysm cases treated by the maze technique and matched cases treated by conventional coil embolization.

Received August 18, 2014; accepted after revision October 23.

From the Department of Neurosurgery, Kokura Memorial Hospital, Fukuoka, Japan.

Please address correspondence to Tsuyoshi Ohta, MD, Department of Neurosurgery, Kokura Memorial Hospital, 3-2-1 Asano, Kokurakita-ku, Kitakyushu, Fukuoka, Japan; e-mail: tsuyoshi@ya2.so-net.ne.jp

http://dx.doi.org/10.3174/ajnr.A4198

\section{MATERIALS AND METHODS}

This was a retrospective study of 42 patients with a large or giant (diameter, $>10 \mathrm{~mm}$ ), ${ }^{3}$ nonthrombosed, unruptured aneurysm who received endovascular treatment at our hospital between February 2007 and December 2013. Eight of these 42 patients were treated after large-diameter coils became available in November 2012 and were treated with the "maze-making and solving" technique (the maze group). Thirty of the previous 34 patients were treated by other techniques (the conventional group). The 4 patients treated by endovascular trapping were excluded. Clinical outcomes were compared between maze and conventional groups.

\section{Angiographic Evaluation}

Aneurysmal location was defined at the origin of the neck on the basis of the classification of Bouthillier et al. ${ }^{4}$ Angiographic findings were evaluated according to the Raymond classification $^{5}$ immediately after surgery and at follow-up. Aneurysm dimensions and volumes were measured by $3 \mathrm{D}$ reformatted images derived from rotational catheter angiograms ${ }^{6}$ by using the Allura 3D-RA workstation (Philips Healthcare, Best, the 

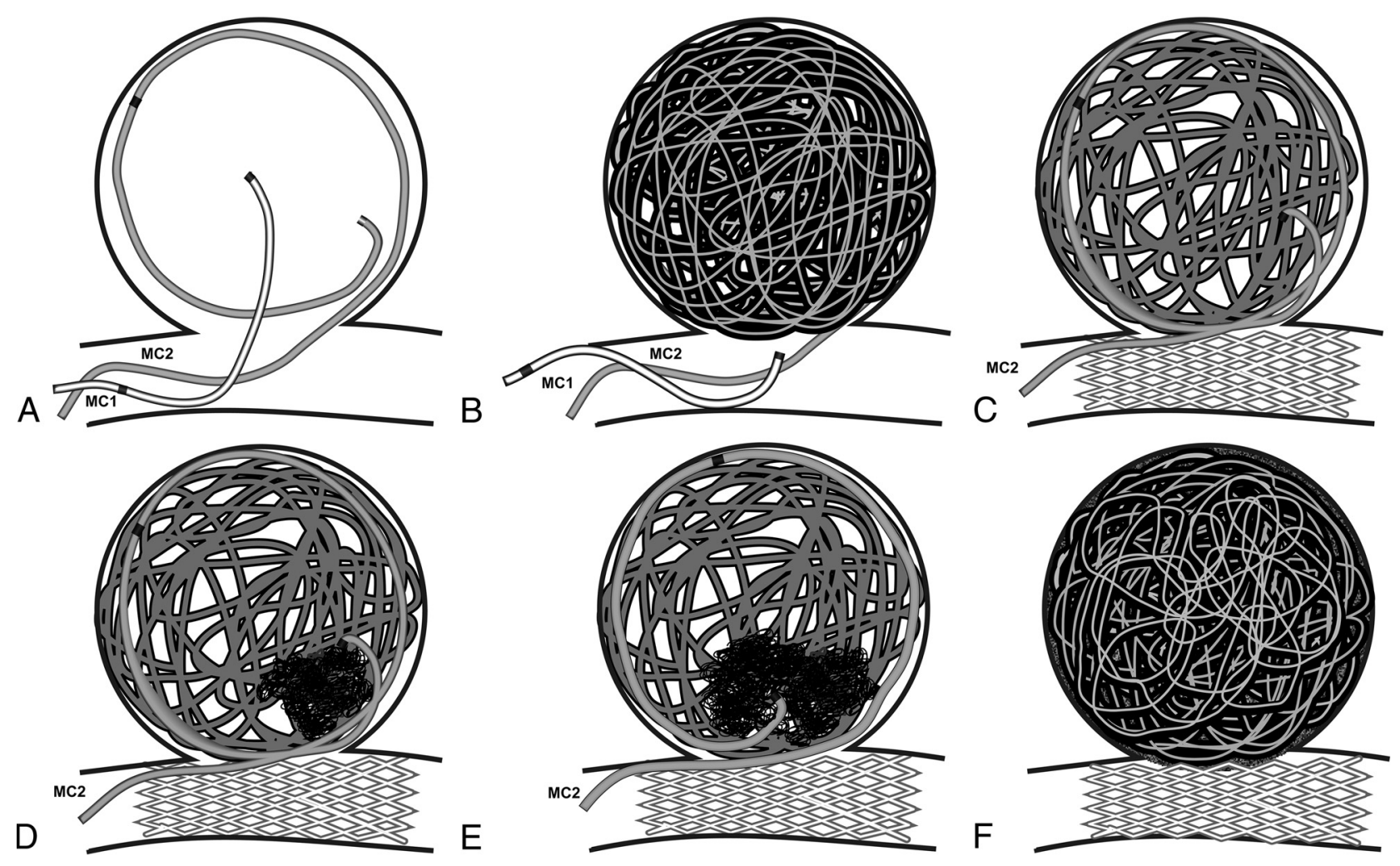

FIG 1. The concept of the maze-making and solving technique. The microcatheter for larger diameter coils (MC1) is placed in the center of the aneurysm, and the catheter for traditional coils (MC2) is placed following the aneurysmal wall to reach beyond the orifice (A). As many as possible larger diameter coils are inserted $(B)$. Cross-section illustrations reveal random interspaces still left unembolized and the movement of MC2 (C-E). Note the elevation of MC2 by stent placement and the second marker of MC2 buried in larger diameter coils $(C)$. Traditional coils from MC2 fill the dead space left unembolized $(D)$. After sufficient filling, the microcatheter is moved back to follow the wall and finds a new space. Note the altered position of the tip and the course of MC2 (E). If we repeat these dead space-filling and wall-follower methods in a stepwise fashion, the aneurysm is tightly embolized $(F)$.

Netherlands). Angiographic recurrence was defined as any worsening of the Raymond classification or enlargement of the residual aneurysm. Angiographic follow-up was performed at 3 months and annually after treatment. When an angiographic recurrence was considered progressive and large enough to embolize again, reintervention was performed. The follow-up period was defined as the number of months postsurgery to recurrence or to the latest angiogram.

\section{Packing Attenuation}

The total volume of the coils deployed into each aneurysm was calculated by multiplying the total length of the coils by the crosssectional area. ${ }^{7}$ Full circumferential expansion was assumed to calculate the volume of hydrogel coils. ${ }^{8}$ Packing attenuation was calculated as the ratio of the total coil volume to the total aneurysm volume.

\section{Clinical Assessment}

Perioperative complications were defined as any new neurologic deficits, serious adverse events extending hospitalization, or death occurring within 30 days after the operation. Periprocedural death and major stroke ( $\mathrm{mRS} \geqq 2$ ) were defined as serious perioperative complications. Clinical follow-up was performed at 1, 3, and 6 months and annually after treatment. Each patient was evaluated by the $\mathrm{mRS}^{9}$ at follow-up, and any worsening was recorded as chronic neurologic deterioration.

\section{Technical Details of the Maze-Making and Solving Technique}

Patients were prescribed aspirin, $100 \mathrm{mg}$, and clopidogrel, $75 \mathrm{mg}$, at least 7 days before their treatment. All treatments were performed with the patient under general anesthesia and systemic heparinization, with an activated clotting time of approximately 300-350 seconds. This technique is a combination of the double-catheter technique, the "one and a half round microcatheterization technique," 10 and various assist techniques. Two microcatheters for aneurysms, 1 balloon catheter and 1 microcatheter for stent placement, are required. One is a microcatheter for larger diameter coils (0.01450.020 inches), such as Penumbra Coil 400 (Penumbra, Alameda, California) or HydroFrame 18 (Terumo, Tokyo, Japan) coils. The other is a microcatheter for traditional coils of $<0.014$ inches in diameter. The microcatheter for larger diameter coils is placed in the center of the aneurysm, and the other, for traditional coils, is placed along the aneurysmal wall to reach beyond the orifice (Fig 1A). Using balloon assistance, we inserted as many larger diameter coils as possible (Fig $1 B$ ). To avoid uneven filling, we inserted larger diameter coils with the movement of the microcatheter by using balloon assistance. This process yields a higher packing attenuation while forming a stable internal frame to support the aneurysm. However, this structure of the larger diameter coils still contains substantial coil-free dead space, leaving much of the aneurysmal space unembolized (Fig 1C).

An aneurysm containing only larger diameter coils resem-

AJNR Am J Neuroradiol 36:744-50 Apr 2015 www.ajnr.org

745 

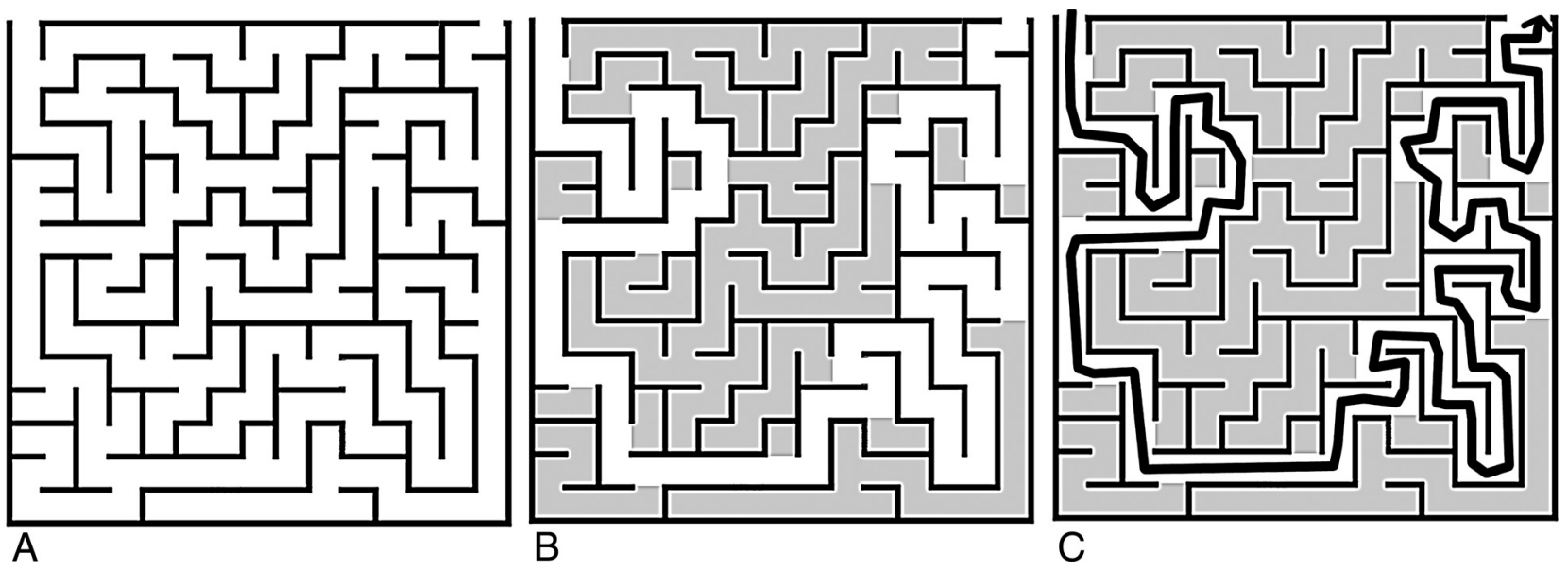

FIG 2. Maze-solving algorithms. The dead space-filling algorithm changes a complex maze $(A)$ to a simple path to reach a goal $(B)$. In combination with the dead space-filling algorithm, the wall-follower algorithm can fill all the spaces inside the maze.

Table 1: Patient characteristics

\begin{tabular}{|c|c|c|c|c|c|c|c|c|c|c|}
\hline \multirow[b]{2}{*}{ Case } & \multirow{2}{*}{$\begin{array}{l}\text { Age/ } \\
\text { Sex }\end{array}$} & \multirow[b]{2}{*}{ Position $^{a}$} & \multirow[b]{2}{*}{ Size (mm) } & \multirow[b]{2}{*}{ Vol (mL) } & \multirow[b]{2}{*}{ Symptoms } & \multirow{2}{*}{$\begin{array}{l}\text { Raymond Class } \\
\text { (Immediate) }\end{array}$} & \multirow[b]{2}{*}{ Postoperative Course } & \multicolumn{2}{|l|}{ PA } & \multirow{2}{*}{$\begin{array}{l}\text { Follow-Up } \\
\text { AG (mo) }\end{array}$} \\
\hline & & & & & & & & Larger Coils & Total & \\
\hline 1 & $77 / F$ & L-ICA (C7) & $20 \times 14 \times 15$ & 1.528 & None & 1 & $\begin{array}{l}\text { Cerebral infarction (mild } \\
\text { hemiparesis and dysesthesia), } \\
\text { mRS } 1\end{array}$ & 34.5 & 41.2 & 12 \\
\hline 2 & $72 / F$ & L-ICA (C4/5) & $24 \times 15 \times 7$ & 3.522 & $\begin{array}{l}\text { Chronic oculomotor } \\
\text { nerve palsy }\end{array}$ & 2 & mRS 0 & 29.1 & 30.4 & 12 \\
\hline 3 & $55 / F$ & R-ICA (C4) & $17 \times 16 \times 13$ & 1.574 & None & 2 & mRS 0 & 35.7 & 38.8 & 19 \\
\hline 4 & $55 / F$ & L-ICA (C6) & $25 \times 24 \times 21$ & 4.991 & $\begin{array}{l}\text { Progressive visual } \\
\text { disturbance }\end{array}$ & 2 & $\begin{array}{l}\text { Cerebral infarction (temporary } \\
\text { dysarthria), worsening of visual } \\
\text { disturbance, mRS } 1\end{array}$ & 26.4 & 32.5 & 17 \\
\hline 5 & $80 / \mathrm{M}$ & L-ICA (C7) & $16 \times 12 \times 11$ & 0.865 & None & 1 & mRS 0 & 24.6 & 40 & 12 \\
\hline 6 & $53 / \mathrm{F}$ & L-ICA (C5) & $15 \times 14 \times 11$ & 0.921 & None & 1 & mRS 0 & 20.2 & 33.9 & 12 \\
\hline 7 & $73 / F$ & $\mathrm{R}-\mathrm{ICA}(\mathrm{C} 7)$ & $13 \times 10 \times 9$ & 0.748 & None & 2 & $\begin{array}{l}\text { Transfusion (hemorrhage from } \\
\text { puncture site), mRS } 0\end{array}$ & 29.3 & 33.8 & 3 \\
\hline 8 & $54 / \mathrm{F}$ & L-ICA (C4/5) & $22 \times 14 \times 15$ & 2.116 & None & 1 & mRS 0 & 37.5 & 48.6 & 3 \\
\hline
\end{tabular}

Note:- R indicates right; L, left; PA, packing attenuation; Vol, volume; AG, angiography.

a The ICA segments are defined according to the classification of Bouthillier et $\mathrm{al}^{4}$

bles a maze with complex random interspaces that could be filled with smaller and softer coils. A maze-solving algorithm was applied to fill up the "maze" (Fig 2A) as much as possible. To solve the maze, we used dead space filling (Fig $2 B$ ) and a wall-follower (Fig 2C) algorithm. Leaving the microcatheter for traditional coils in place, we exchanged the balloon catheter with a microcatheter for stent placement and then positioned a stent to cover the aneurysm neck. Stent stabilization contributes to the controlled movement of the other microcatheter left inside the aneurysm. As shown by a cross-section illustration (Fig 1D), traditional smaller coils can be inserted into the dead space between the larger diameter coils. After sufficient filling, the microcatheter is moved back along the wall of the aneurysm to fill another space left unembolized (Fig 1E). However, the movement of these traditional coils cannot be visualized clearly, and the second marker of the microcatheter is usually hidden inside the already packed aneurysm. Thus, the first traditional coils inserted should have infiltrating capacity and be equipped with a monopolar detachment system that can indicate detachment by sound. We usually start with ED Coil-10 Infini Extra Soft coils (Kaneka Medix, Osaka, Japan), which have both features. ${ }^{11,12}$ These coils are very soft and have high plasticity and a stretch-resistant structure, allowing them to fit within small irregular spaces. ${ }^{10}$ If we repeat the dead space-filling and wall-follower steps, the maze is finally "solved" to achieve the highest possible coil-packing attenuation (Fig $1 F)$.

\section{Statistical Analysis}

The Fisher exact test or Student $t$ test, as appropriate, was used to compare group means. The Fisher exact test was used for categoric data such as sex, location, angiographic recurrence, perioperative complications, periprocedural death, major stroke, or reintervention. The Student $t$ test was used for continuous variables such as packing attenuation, maximum diameter, aneurysm volume, and number of coils. A $P$ value $<.05$ was considered significant. The $P$ value is expressed as 2 significant figures; if the value is $<.01$, then it is expressed as $P<.01$. All analyses were performed by using js-STAR 2012 (www.kisnet.or.jp/nappa/software/star).

\section{RESULTS \\ Comparison between the Maze Group and the Conventional Group}

Characteristics of Patients and Aneurysms. All 8 aneurysms treated by the maze-making and solving technique were located along the ICA. Two patients had symptoms of cranial nerve palsy due to a mass effect, one chronic and the other acute. A detailed summary of patient demographic and clinical characteristics is presented in Table 1. 


\begin{tabular}{|c|c|c|c|c|c|}
\hline & $\begin{array}{l}\text { Maze Group } \\
\quad(n=8)\end{array}$ & $\begin{array}{c}\text { Conventional } \\
\text { Group } \\
(n=30)\end{array}$ & $\begin{array}{l}\text { Conventional } \\
\text { Group Using } \\
\text { Intracranial } \\
\text { Stents }(n=15)\end{array}$ & $\begin{array}{c}P \text { Value between } \\
\text { Maze Group and } \\
\text { Conventional Group }\end{array}$ & $\begin{array}{c}\text { P Value between Maze } \\
\text { Group and } \\
\text { Conventional Group } \\
\text { Using Intracranial } \\
\text { Stents }\end{array}$ \\
\hline Age & $65 \pm 11.5$ & $65.4 \pm 13.0$ & $68.3 \pm 13.2$ & .93 & .56 \\
\hline Sex (male:female) & $1: 7$ & $8: 22$ & $3: 12$ & .29 & .41 \\
\hline Location (ICA:others) & $8: 0$ & $20: 10$ & $8: 7$ & .064 & $.026^{\mathrm{a}}$ \\
\hline Packing attenuation (\%) & $37.4 \pm 5.9$ & $26.2 \pm 5.6$ & $27.9 \pm 4.6$ & $<.01^{\mathrm{a}}$ & $<.01^{\mathrm{a}}$ \\
\hline Maximum diameter (mm) & $19 \pm 4.4$ & $13.4 \pm 3.8$ & $13.9 \pm 5.0$ & $<.01^{\mathrm{a}}$ & $.02^{\mathrm{a}}$ \\
\hline Aneurysm volume (mL) & $2.03 \pm 1.40$ & $1.09 \pm 1.52$ & $1.38 \pm 2.12$ & .13 & .41 \\
\hline No. of coils & $33.3 \pm 16.1$ & $15.5 \pm 10.1$ & $18.7 \pm 12.4$ & $.017^{\mathrm{a}}$ & $.047^{\mathrm{a}}$ \\
\hline Angiographic recurrence & 0 & 11 & 3 & $.036^{\mathrm{a}}$ & .26 \\
\hline Perioperative complications & 3 & 2 & 5 & .31 & .34 \\
\hline $\begin{array}{l}\text { Periprocedural death or } \\
\text { major stroke }\end{array}$ & 0 & 5 & 3 & .28 & .26 \\
\hline Reintervention & 0 & 4 & 2 & .34 & .41 \\
\hline
\end{tabular}

a Significant $P$ value.

The conventional group included 30 patients, 15 treated by balloon-assisted coil embolization and the remaining 15 , by stentassisted coil embolization. Mean age did not differ between maze and conventional groups $(65 \pm 11.5$ years versus $65.4 \pm 13.0$ years), though the conventional group included more men (12.5\% versus $26.7 \%)$ and patients with aneurysms outside the ICA ( $0 \%$ versus $33.3 \%$ ). Mean maximum aneurysm diameter of the maze group was significantly larger than that of the conventional group $(19 \pm 4.4 \mathrm{~mm}$ versus $13.4 \pm 3.8 \mathrm{~mm}$ ) (Table 2).

Clinical Outcomes. In the maze group, perioperative complications occurred in 3 cases (37.5\%), including 1 case of cerebral infarction with minor hemiparesis and dysesthesia (case 1), 1 case of cerebral infarction with dysarthria and worsening of visual symptoms due to an increased mass effect (case 4), and 1 case requiring blood transfusion due to hemorrhage at the puncture site (case 7). By 1 month postsurgery, most neurologic symptoms had improved, with the remaining sequelae including minor dysesthesia (case 1, mRS 1) and slightly worsened visual symptoms (case 4, mRS 1). All patients were able to resume their previous lives (mRS 0 or 1 ). No patient showed chronic neurologic deterioration.

In the conventional group, perioperative complications occurred in 12 patients (40\%), including 6 cases of cerebral infarction, 1 case of cerebral infarction and subarachnoid hemorrhage, 2 cases of subarachnoid hemorrhage, 1 case of massive hematoma at the puncture site, 1 case of progressive dementia, and 1 case of delayed allergic vasculitis against platinum coils. Four cases showed serious perioperative complications, including 2 deaths due to immediate postoperative subarachnoid hemorrhage and massive cerebral infarction.

Angiographic Outcomes. Four "maze" treatments resulted in complete obliteration of the aneurysm (Raymond class 1), and 4 patients were left with a residual neck (Raymond class 2) as revealed by angiograms obtained immediately after surgery. The mean total number of coils inserted was $33.3 \pm 16.1$. The mean packing attenuation after the insertion of the larger diameter coils was $29.7 \pm 5.9 \%$, and the mean total packing attenuation following insertion of the smaller coils was $37.4 \pm 5.9 \%$. Angiographic follow-up at $11.3 \pm 5.4$ months after the operation revealed that the aneurysms were well-secured with no recurrences.
In the conventional group, mean packing attenuation was $26.2 \pm$ $5.6 \%$ and the mean number of coils inserted was $15.5 \pm 10.1$. Treatment resulted in complete obliteration of the aneurysm (class 1 ) in 17 cases, a residual neck (class 2 ) in 10 cases, and residual aneurysm (class 3 ) in 3 cases as revealed by immediate postsurgical angiography. Of the remaining 28 patients, excluding 2 deaths, from the group of 30 patients, angiographic recurrence was observed in 11 $(39.3 \%)$ at $5.2 \pm 3.2$ months and reintervention was performed in 4 patients (14.3\%).

Although the mean maximum aneurysm diameter and volume were smaller in the conventional group $(P<.01$ and $P=.13$, respectively), we achieved significantly higher packing attenuation in the maze group $(P<.01)$. While there was no significant difference in the rate of reintervention $(P=.35)$, there was a significantly lower rate of recurrence in the maze group as revealed by angiography $(P=$ .036).

\section{Comparison between the Maze Group and the Conventional Group Using Intracranial Stents}

Because the conventional group included 15 cases of coil embolization that were not assisted by a stent, we compared the results between the maze group and the conventional group for cases using intracranial stents $(n=15$, Table 2$)$. Mean age $(65 \pm 11.5$ years in the maze group versus $68.3 \pm 13.2$ years in the conventional group using intracranial stents) and sex ratio (male/female $=1: 7$ versus 3:12) did not differ between the groups, though the conventional group included significantly more patients with aneurysms outside the ICA ( $0 \%$ versus $46.7 \%, P=.026)$ than the maze group. Packing attenuation $(37.4 \pm 5.9 \%$ versus $27.9 \pm 4.6 \%, P<.01)$, maximum diameter $(19 \pm 4.4 \mathrm{~mm}$ versus $13.9 \pm 5.0 \mathrm{~mm}, P=.02)$, and number of coils $(33.3 \pm 16.1$ versus $18.7 \pm 12.4, P=.047)$ were significantly larger in the maze group than in the conventional group using intracranial stents. The aneurysm volume $(2.03 \pm 1.40 \mathrm{~mL}$ versus $1.38 \pm$ $2.12 \mathrm{~mL}$ ) and the rates of perioperative complications (37.5\% versus $33.3 \%)$, periprocedural death or major stroke ( $0 \%$ versus $20 \%$ ), and reintervention ( $0 \%$ versus $13.3 \%$ ) did not differ between the groups. Angiographic recurrence ( $0 \%$ versus 20\%) was more common in the conventional group using intracranial stents, but this difference was not significant $(P=.26)$. 

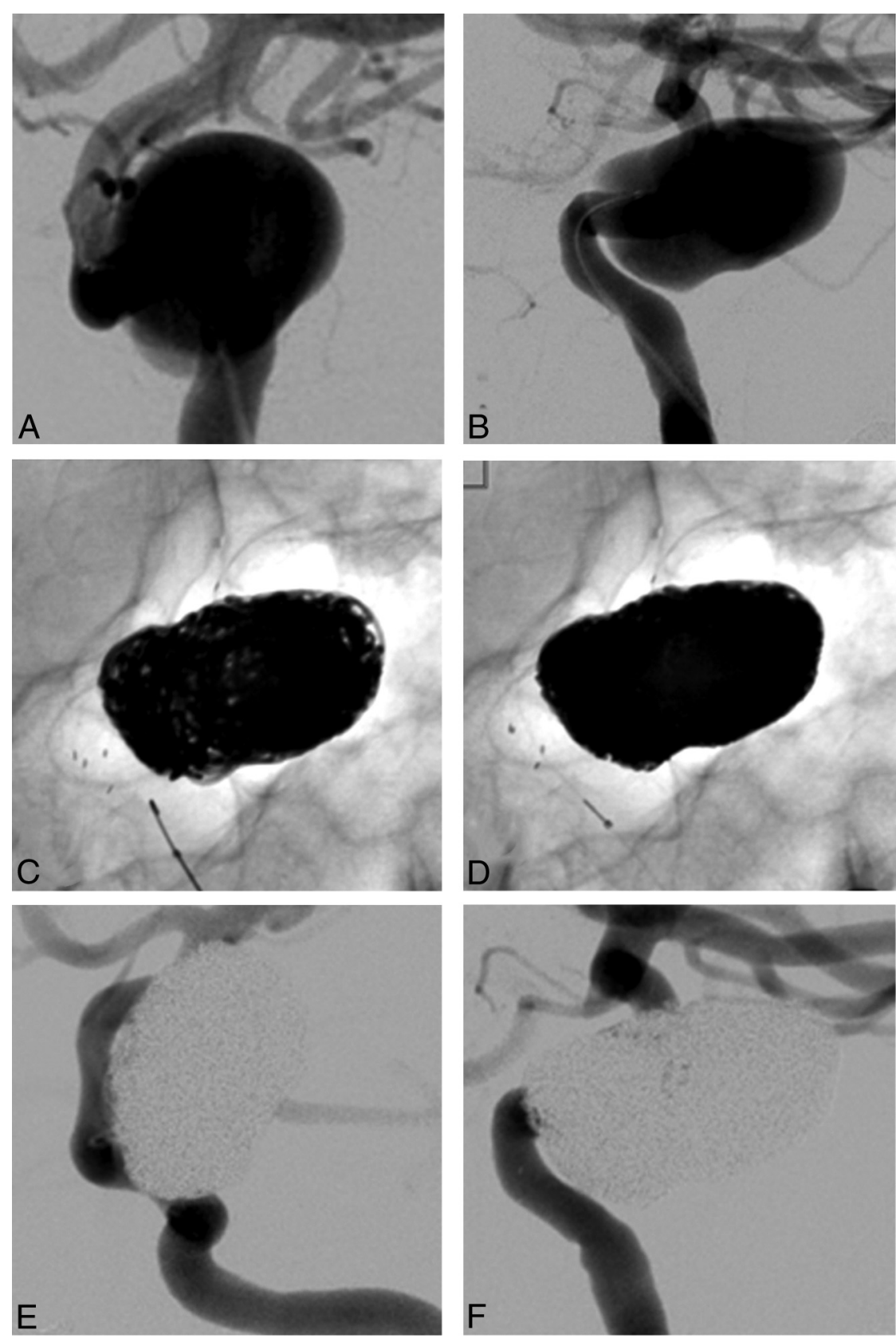

FIG 3. Representative case. Cerebral angiography reveals a left internal carotid artery large aneurysm in anteroposterior $(A)$ and lateral $(B)$ views. The Penumbra Coil 400 makes a maze with random interspaces between the coils $(C)$, which is solved by the addition of traditional coils $(D)$. Postoperative cerebral angiography reveals complete obliteration in anteroposterior $(E)$ and lateral $(F)$ views.

\section{Representative Case}

A large aneurysm (maximum diameter, $22 \mathrm{~mm}$ ) was found along the left ICA (Fig 3A, - B) in a 54-year-old woman during examination for head injury. After thorough discussion, she opted for surgical intervention. After a 14-day treatment with aspirin, $100 \mathrm{mg}$, and clopidogrel, $75 \mathrm{mg}$, an $8 \mathrm{~F}$ sheath was placed in her right femoral artery under general anesthesia and injected with heparin to reach $>300$-seconds activated clotting time. An 8 F guiding catheter was advanced in the left ICA, and a 15-mm balloon catheter was positioned to cover the neck of the aneurysm. A PX Slim Delivery Microcatheter ( $45^{\circ}$ shape; Penumbra) was placed in the center of the aneurysm, and the other microcatheter for traditional coils was positioned to reach beyond the orifice and follow the aneurysm wall. Using the balloon-assisted technique, we inserted 11 Penumbra Coil 400 coils, resulting in a packing attenuation of $37.5 \%$, and the PX Slim microcatheter was retracted from the aneurysm into the ICA (Fig 3C). To stabilize the other microcatheter still inside the aneurysm, we placed a 20 -mm stent over the orifice. From the other microcatheter inside the aneurysm, 26 ED Coil-10 Infini Extra Soft coils were inserted until the second marker was visible again on angiography. An additional 9 traditional coils were added (Fig 3D) to reach a packing attenuation of $48.6 \%$ and complete aneurysm obliteration (Raymond class 1 ) as revealed by angiography (Fig $3 E,-F)$. She returned to her previous life without any complications. Angiographic findings at 3 months and MRA at 6 months postsurgery showed no recurrence.

\section{DISCUSSION}

The maze-making and solving technique enabled a higher coil-packing attenuation in large and giant aneurysms than that achieved by conventional balloon- or stent-assisted coil placement, possibly accounting for the significantly lower angiographic recurrence rate.

The natural course of an unruptured cerebral aneurysm is influenced by size, ${ }^{13,14}$ and larger cerebral aneurysms have a poor prognosis, with a high risk of subarachnoid hemorrhage or progressive symptoms due to a mass effect. ${ }^{15}$ In addition, large and giant aneurysms often have thicker atheromatous walls that prevent simple neck clipping. ${ }^{16}$ Several treatment strategies, such as parent vessel occlusion, selective aneurysmal occlusion, and application of a flow-diverting stent, have been used for the treatment of large and giant aneurysms. In some cases, parent vessel occlusion may be the best choice. However, de novo aneurysm formation has been reported after carotid artery occlusion. ${ }^{17}$ When the patient cannot tolerate parent vessel occlusion, bypass surgery should be performed. However, bypass surgery requires exceptional surgical skills, and the incidence of operative complications resulting in neurologic deficits or death was reported to be as high as $13 \% .^{18}$

Almost all previous studies of selective coiling of large and giant aneurysms have reported some reopening due to low packing attenuation. ${ }^{15}$ Selective occlusion with Onyx (Covidien, Ir- 
vine, California) has also been used ${ }^{19,20}$; however, the outcomes were no better than selective coil occlusion, and the immediate and delayed complication rate was considered higher than that in the present study.

In the case series, a flow-diverting stent was not an option because our government has not yet authorized this treatment. Flow-diverting stent placement is a promising therapy for challenging intracranial aneurysms, including large and giant aneurysms. However, permanent morbidity and mortality were reported to be $5.6 \%-10.8 \% .^{6,21}$ Moreover, flow-diverting stent surgery for posterior circulation aneurysms resulted in more patients with ischemia due to perforator occlusion ${ }^{22}$; therefore, a more effective strategy is required, particularly for large and giant posterior circulation aneurysms.

Some practitioners have reported that moderate packing attenuation $(12 \%-22 \%)$ should be sufficient, but this may apply only to stent-assisted coil embolization of smaller aneurysms. ${ }^{23}$ Most aneurysms packed to approximately $\geq 25 \%$ remain stable at follow-up. ${ }^{24}$ Initial studies of Penumbra Coil 400 insertion into smaller aneurysms reported packing attenuation as high as $33.7 \%{ }^{25}$ and $36.8 \% .{ }^{26}$ Our procedure also attained such high attenuation $(37.4 \%)$ but on large and giant aneurysms for which higher packing attenuation has proved difficult to achieve. When we used the maze-making and solving technique, higher coilpacking attenuation was facilitated by the addition of traditional smaller coils $(7.7 \%)$, following the insertion of larger diameter coils $(29.7 \%)$.

Of the 8 patients treated by this new technique, 3 showed postoperative morbidity. However, all cases were minor, with 1 at mRS 0 and 2 at mRS 1 . Moreover, no deaths were observed. After the augmentation of intraoperative anticoagulation therapy, we did not encounter further ischemic complications. One patient had postoperative worsening of optic nerve dysfunction, which resolved only slightly within 6 months. A previous study found that the selective coiling of unruptured large and giant carotid artery aneurysms presenting with cranial nerve palsy was as effective as parent artery occlusion and was associated with a greater chance of symptom improvement. ${ }^{27}$

The basic principle behind the maze-making and solving technique is to first construct a complex framework of larger diameter coils inside the aneurysm and then to fill the unembolized spaces within this large coil framework with traditional (smaller) coils by using a second microcatheter left inside the aneurysm. Although larger diameter coils occupy more volume than traditional coils, they also leave larger interspaces. However, larger diameter coils support the aneurysm; such a structure is less likely to collapse. While a new microcatheter cannot enter the aneurysm, the microcatheter already inside is unlikely to dislodge due to support by the coils and the subsequently introduced stent. The double-microcatheter technique is used to produce satisfactory occlusion by bracing 2 coils within the aneurysm, ${ }^{28}$ but that does not discriminate the role of each microcatheter. The "one and a half round microcatheterization technique" 10 is used to position the second microcatheter for maze-solving. This technique alone may produce a high packing attenuation. However, controlling the movement of the microcatheter can be difficult, and the microcatheter may easily fall to the edge of the stent. If this technique is used after forming the maze, the complexity of the structure will prevent unnecessary movement of the second microcatheter and dropout from the aneurysm. Solving this large coil maze by wall-following and dead space-filling algorithms allowed higher coilpacking attenuation. The order of insertion is important. If traditional coils were used for making the maze, they could not provide enough volume, whereas larger diameter coils cannot fill the interspaces left by smaller coils. Thus, the specific combination of large- and smaller-diameter coils is necessary for the success of this technique.

A long-term follow-up study indicated that using stents in endovascular treatments provided high rates of complete occlusion with low rates of recurrence ${ }^{29}$; therefore, the positive results observed in the maze group in the present study may be due to intracranial stents. We also analyzed the maze and the conventional groups using intracranial stents separately. Although angiographic recurrence rates did not reach significant differences, the maximum diameter and packing attenuation were significantly larger in the maze group than in the conventional group using intracranial stents. This outcome indicates that the contribution of stents is apparent but partial. In a particularly large or giant aneurysm, the maze-making and solving technique can be a better choice to reach a higher packing attenuation than with intracranial stents alone.

The major limitations of our study are the short follow-up period (11.3 \pm 5.4 months $)$ and small number of patients. However, recurrence in the conventional group occurred at $5.2 \pm 3.2$ months postsurgery; therefore, we monitored the patients in the maze group beyond the period of highest recurrence risk. In addition, because ED coils are for sale only in Japan, the selection of the smaller coils for the second microcatheter may be more difficult in other countries. This technique also requires more coils and thus increases the cost, but this extra surgical cost is justified if recurrence is reduced. Our technique may be applicable to aneurysms in other regions, such as the treatment of posterior circulation aneurysms. However, our cases included only anterior circulation aneurysms.

\section{CONCLUSIONS}

By the maze-making and solving technique, we attained high coilpacking attenuation for coil embolization of large and giant aneurysms. Moreover, we observed low recurrence rates compared with the traditional coil embolization of large or giant aneurysm without any significant increases in perioperative complications. This is a promising treatment method and may result in longer stability to avoid further intervention.

\section{ACKNOWLEDGMENTS}

We express our gratitude to Drs Takuya Okata, Kazutaka Sonoda, and Junpei Koge for useful and constructive comments and suggestions.

Disclosures: Tsuyoshi Ohta-UNRELATED: Consultancy: Terumo, Kaneka, Comments: None exceeds the criteria for self-reported conflict of interest disclosure according to the Ethical Guidelines for Clinical Research (Ministry of Labor, Health, and Welfare of Japan); Payment for Lectures (including service on Speakers Bureaus): Stryker, Kaneka, Cordis, Mochida, Otsuka, Comments: None exceeds the criteria for self-reported conflict of interest disclosure according to the Ethical Guidelines for Clinical Research (Ministry of Labor, Health, and Welfare of Japan). 
Ichiro Nakahara-UNRELATED: Consultancy: Terumo, Covidien, Johnson \& Johnson, Kaneka, Comments: Consultant fee was paid to me by each neurointerventional device company. Each fee was less than $\$ 10,000$ per year and did not meet the criteria for declaration of conflict of interest by the Japanese Society of Neurosurgery and Japanese Society for Neuroendovascular Therapy. Hidehisa Nishi-UNRELATED: Payment for Lectures (including service on Speakers Bureaus): Boehringer Ingelheim, Comments: None exceeds the criteria for self-reported conflict of interest disclosure according to the Ethical Guidelines for Clinical Research (Ministry of Labor, Health, and Welfare of Japan).

\section{REFERENCES}

1. McDougall CG, Johnston SC, Gholkar A, et al. Bioactive versus bare platinum coils in the treatment of intracranial aneurysms: the MAPS (Matrix and Platinum Science) trial. AJNR Am J Neuroradiol 2014;35:935-42

2. Raymond J, Klink R, Chagnon M, et al. Patients prone to recurrence after endovascular treatment: periprocedural results of the PRET randomized trial on large and recurrent aneurysms. AJNR Am J Neuroradiol 2014;35:1667-76

3. Choi IS, David C. Giant intracranial aneurysms: development, clinical presentation and treatment. Eur J Radiol 2003;46:178-94

4. Bouthillier A, van Loveren HR, Keller JT. Segments of the internal carotid artery: a new classification. Neurosurgery 1996;38:425-32; discussion 432-33

5. Roy D, Milot G, Raymond J. Endovascular treatment of unruptured aneurysms. Stroke 2001;32:1998-2004

6. Becske T, Kallmes DF, Saatci I, et al. Pipeline for uncoilable or failed aneurysms: results from a multicenter clinical trial. Radiology 2013;267:858-68

7. Bendok BR, Parkinson RJ, Hage ZA, et al. The effect of vascular reconstruction device-assisted coiling on packing density, effective neck coverage, and angiographic outcome: an in vitro study. $\mathrm{Neu}$ rosurgery 2007;61:835-40; discussion 840-41

8. Speirs JW, Burke TH, Lee SY, et al. The next generation HydroCoil: initial clinical experience with the HydroFill embolic coil. J Neurointerv Surg 2013;5(suppl 3):iii72-75

9. Banks JL, Marotta CA. Outcomes validity and reliability of the modified Rankin Scale: implications for stroke clinical trials - a literature review and synthesis. Stroke 2007;38:1091-96

10. Miyachi S, Matsubara N, Izumi T, et al. The 'one and a half round microcatheterization technique' for stent-assisted coil embolization of intracranial aneurysm: technical case series. J Neurointerv Surg 2014;6:357-62

11. Harada K, Morioka J. Initial experience with an extremely soft bare platinum coil, ED coil-10 Extra Soft, for endovascular treatment of cerebral aneurysms. J Neurointerv Surg 2013;5:577-81

12. Fukuda H, Miyake K, Kunieda T, et al. Endovascular treatment of sphenoid wing dural arteriovenous fistula with pure cortical venous drainage. J Stroke Cerebrovasc Dis 2014;23:1730-35

13. Morita A, Kirino T, Hashi K, et al, for the UCAS Japan Investigators. The natural course of unruptured cerebral aneurysms in a Japanese cohort. N Engl J Med 2012;366:2474-82
14. Wiebers DO, Whisnant JP, Huston J 3rd, et al. Unruptured intracranial aneurysms: natural history, clinical outcome, and risks of surgical and endovascular treatment. Lancet 2003;362:103-10

15. van Rooij WJ, Sluzewski M. Endovascular treatment of large and giant aneurysms. AJNR Am J Neuroradiol 2009;30:12-18

16. Nussbaum ES, Nussbaum LA. A novel aneurysm clip design for atheromatous, thrombotic, or previously coiled lesions: preliminary experience with the "compression clip" in 6 cases. Neurosurgery 2010;67:333-41

17. Arambepola PK, McEvoy SD, Bulsara KR. De novo aneurysm formation after carotid artery occlusion for cerebral aneurysms. Skull Base 2010;20:405-08

18. Brilstra EH, Rinkel GJ, Klijn CJ, et al. Excimer laser-assisted bypass in aneurysm treatment: short-term outcomes. J Neurosurg 2002;97: 1029-35

19. Molyneux AJ, Cekirge S, Saatci I, et al. Cerebral Aneurysm Multicenter European Onyx (CAMEO) trial: results of a prospective observational study in 20 European centers. AJNR Am J Neuroradiol 2004;25:39-51

20. Weber W, Siekmann R, Kis B, et al. Treatment and follow-up of 22 unruptured wide-necked intracranial aneurysms of the internal carotid artery with Onyx HD 500. AJNR Am J Neuroradiol 2005;26: 1909-15

21. Berge J, Biondi A, Machi P, et al. Flow-diverter Silk stent for the treatment of intracranial aneurysms: 1-year follow-up in a multicenter study. AJNR Am J Neuroradiol 2012;33:1150-55

22. Brinjikji W, Murad MH, Lanzino G, et al. Endovascular treatment of intracranial aneurysms with flow diverters: a meta-analysis. Stroke 2013;44:442-47

23. Chalouhi N, Dumont AS, Hasan D, et al. Is packing density important in stent-assisted coiling? Neurosurgery 2012;71:381-86; discussion 386-87

24. Sluzewski M, van Rooij WJ, Slob MJ, et al. Relation between aneurysm volume, packing, and compaction in 145 cerebral aneurysms treated with coils. Radiology 2004;231:653-58

25. Milburn J, Pansara AL, Vidal G, et al. Initial experience using the Penumbra Coil 400: comparison of aneurysm packing, cost effectiveness, and coil efficiency. J Neurointerv Surg 2014;6:121-24

26. Mascitelli JR, Polykarpou MF, Patel AA, et al. Initial experience with Penumbra Coil 400 versus standard coils in embolization of cerebral aneurysms: a retrospective review. J Neurointerv Surg 2013;5:573-76

27. van Rooij WJ, Sluzewski M. Unruptured large and giant carotid artery aneurysms presenting with cranial nerve palsy: comparison of clinical recovery after selective aneurysm coiling and therapeutic carotid artery occlusion. AJNR Am J Neuroradiol 2008;29:997-1002

28. Baxter BW, Rosso D, Lownie SP. Double microcatheter techniques for detachable coil treatment of large, wide-necked intracranial aneurysms. AJNR Am J Neuroradiol 1998;19:1176-78

29. Geyik S, Yavuz K, Yurttutan N, et al. Stent-assisted coiling in endovascular treatment of 500 consecutive cerebral aneurysms with long-term follow-up. AJNR Am J Neuroradiol 2013;34:2157-62 